\title{
POTENCIALIDADE DOS GRANITOS PORFIRÍTICOS DO COMPLEXO SOROCABA (SP) PARA USO COMO ROCHAS ORNAMENTAIS E PARA REVESTIMENTO
}

\author{
ANTONIO MISSON GODOY ${ }^{1}$, JÚLIO CÉSAR DE PINHEIRO ARRAIS ${ }^{2}$, LARISSA MARQUES \\ BARBOSA DE ARAÚJO-RUIZ ${ }^{2} \&$ FABIANO CABAÑAS NAVARRO ${ }^{2}$
}

\begin{abstract}
Resumo O estudo das rochas do Complexo Granitóide Porfirítico Sorocaba visando a avaliação de seu potencial como material ornamental e para revestimento baseou-se na caracterização dos aspectos mineralógicos, petrográficos, litogeoquímicos e tecnológicos (físicos-mecânicos) dos seus principais litotipos que apresentam exeqüibilidade de lavra. Estes estudos visaram a possibilidade de se ampliar a oferta de novas variedades estéticas de rochas com a adequada identificação, tipificação e caracterização tecnológica. São apresentados indicadores da potencialidade como rocha para revestimento, dentre os quais se destacam: ampla distribuição geológica e geográfica e ocorrências com diversidade de subtipos de rochas favoráveis à utilização como rochas ornamentais. A proximidade ao maior pólo consumidor de rochas do país (a cidade de São Paulo) e aos portos exportadores; proximidade de municípios desenvolvidos para a implantação de estações de desdobramento e beneficiamento; e propriedades tecnológicas mínimas desejáveis para utilização como material para revestimento de edificações. Este conjunto de fatores poderá ampliar a atividade minerária no setor para o Estado de São Paulo e contribuir para transformá-lo de grande consumidor em grande centro produtor e exportador de rochas ornamentais e para revestimento.
\end{abstract}

Palavras-Chave: Complexo Sorocaba, Propriedades Tecnológicas, Rocha Ornamental, Granito.

\begin{abstract}
POTENCIAL OF PORPHYRITIC GRANITES FROM THE SOROCABA COMPLEX (SP) FOR USE AS DIMENSION STONES Geological studies of the rocks from the Sorocaba Porphyritic Granite Complex for qualification as dimension stones and covering materials was carried out based on structural, mineralogical, petrographic, lithogeochemical and technological aspects presenting the mining potential of the rocks. The physical and mechanical characterizations point to the possibility of increasing the offer of new varieties of rocks for dimension stones, based on correct analysis, aiming to get technical solutions and orientation for the correct application and prevention of architectural problems. Furthermore, those rocks show wide geological and geographical distribution and the largest occurrences and diversity of favorable rock subtypes. The proximity to the largest consuming pole, the São Paulo City, and to the exporting ports would make it possible for São Paulo State to change from major consumer to a major producer and exporter of dimension stones.
\end{abstract}

Keywords: Sorocaba Complex, Technological Properties, Dimension Stone, Granite.

INTRODUÇÃO O segmento de rochas ornamentais é atualmente uma área do setor mineral que apresenta reflexo de um crescimento acelerado, devido principalmente à intensificação da aplicação de rochas como elemento de revestimento, especialmente de fachadas. O crescimento constante desse setor ao longo dos últimos anos tem sido marcado pela competitividade e pelo nível de exigência do mercado consumidor, fatores que requerem a intensificação de pesquisas contemplando a oferta de rochas com novas variedades estéticas e que tenham atributos mínimos quanto às propriedades tecnológicas, visando à adequada aplicação.

Observa-se que o Estado de São Paulo encontra-se entre os menores produtores nacionais, contribuindo na fase inicial de produção (lavra) com apenas (1\%), através de centros produtores tradicionais e localizados, enquanto na fase final de consumidor ou de produto processado (marmorarias), destacase preferencialmente com aproximadamente 50\% (IPT 2000). Considerando a expressiva distribuição geológica e geográfica das ocorrências de rochas graníticas e/ou granitóides com textura porfirítica no Estado de São Paulo, e a aceitação de padrões semelhantes pelo mercado consumidor (ex. o tipo Amêndoa Sorocaba), tem-se que rochas desse tipo apresentam uma boa fronteira de mercado.

Neste sentido, o trabalho aponta ocorrências de rochas com textura porfirítica do Complexo Sorocaba (Figura 1) estudado inicialmente por Godoy (1989) e que apresentam potencial como material de revestimento, visto o conjunto de características estéticas, petrográficas e tecnológicas que reúnem. Acrescenta-se ainda que as ocorrências, ora descritas, apresentam aspectos geológicos e geomorfológicos favoráveis à extração mineral, tais como morros com delgada cobertura de solo e matacões de dimensões amplas. Outro ponto favorável é a localização privilegiada próxima as cidades com boa infra-estrutura, como Sorocaba e São Roque, que permitem a instalação de unidades para o desdobramento e processamento dos materiais, aliado ainda, a proximidade de grandes centros consumidores como as cidades de Campinas e São Paulo, bem como aos grandes portos exportadores.

Os estudos neste Complexo consistem na continuidade das pesquisas já desenvolvidas com as rochas granitóides na região sudeste do Estado de São Paulo, que, numa primeira etapa, geraram extenso conjunto de dados geológicos, mineralógicos, petrográficos, estruturais e geoquímicos. Portanto, nesta nova etapa, o objetivo principal é a caracterização dos parâmetros tecnológicos, os quais serão utilizados em conjunto com as demais informações revisadas e interpretadas seguindo um enfoque específico da aplicação dessas rochas como material ornamental e para revestimento, cabendo em fases futuras, estudos adequados para cubagem de cada padrão estético identificado, ou mesmo ampliação dos estudos para demais fácies que nesta primeira avaliação não foram selecionadas como prioritárias.

As características estéticas das rochas provenientes desse complexo apresentam boa aceitação por parte do mercado consumidor e uma gama variada de padrões estéticos, além de um volume expressivo e passível de lavra.

Para as rochas estudadas observa-se que a variação do pa- 


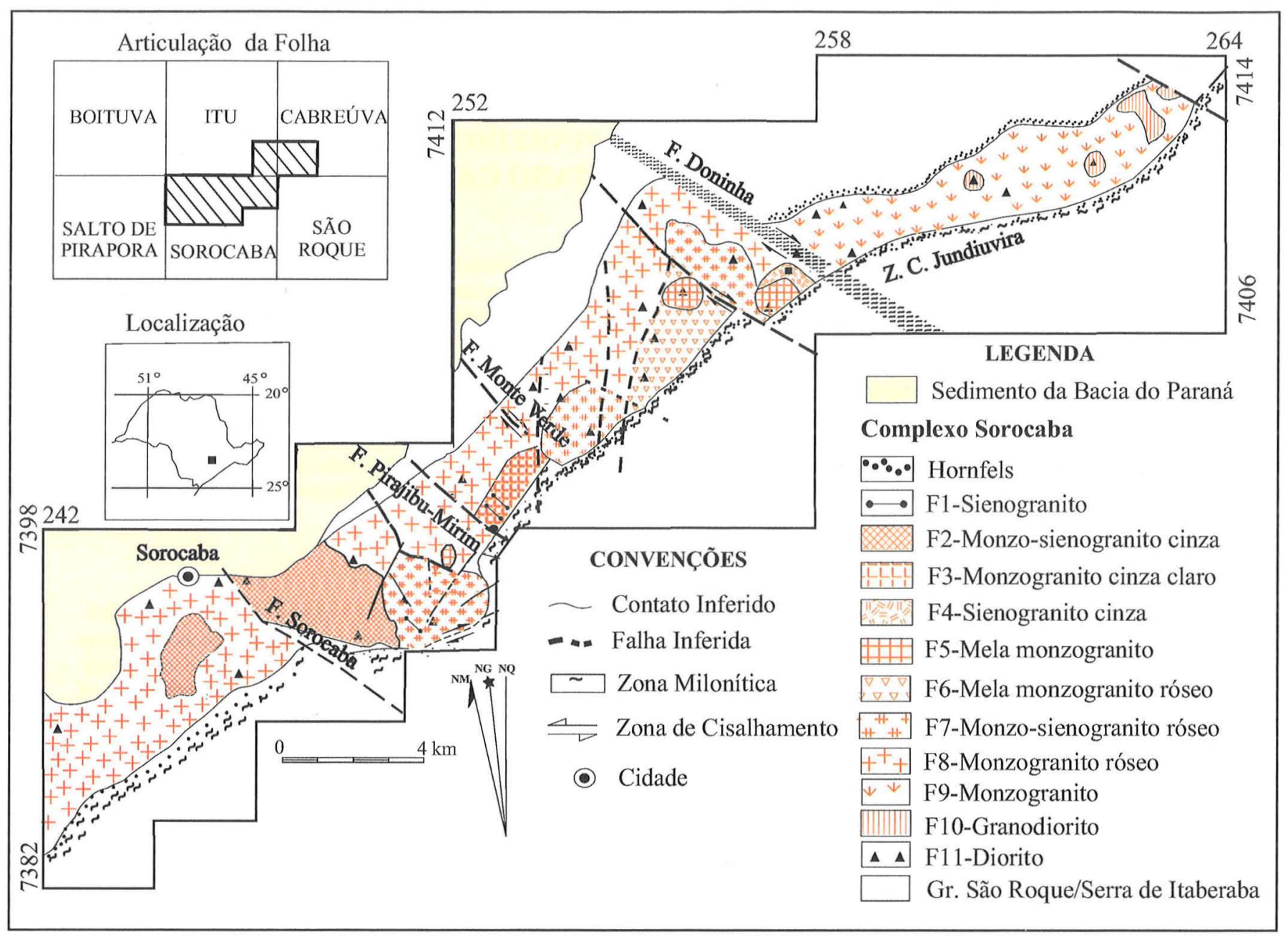

Figura 1: Mapa Geológico do Complexo Sorocaba (SP) (Godoy 1989).

drão estético é um reflexo direto das variações das texturas porfiríticas, fruto das diferentes combinações de composição e granulação da matriz, e principalmente composição, freqüência e tamanho médio dos fenocristais. As combinações desses fatores acarretam também respostas diferentes nos ensaios físicos e mecânicos, necessitando estudos adequados de caracterização tecnológica para a correta aplicação desses materiais, evitando eventuais problemas tecnológicos.

Espera-se que os dados preliminares destas ocorrências, ora apresentados e discutidos, contribuam para a motivação da aplicação de rochas com texturas porfiríticas como material de revestimento, salientando a necessidade de critérios adequados de nomenclatura comercial e especificação técnica.

ASPECTOS GEOLÓGICOS E PETROGRÁFICOS Os estudos anteriores do Complexo Granitóide Sorocaba resultam da integração de mapeamentos geológicos em escala 1:25.000 e 1:50.000 de áreas correspondentes das folhas topográficas Sorocaba, Itu, e Cabreúva, região sudeste do Estado de São Paulo, nas proximidades da cidade de Sorocaba. A região é constituída pelas rochas encaixantes da Seqüência Metavulcano-sedimentar do Grupo São Roque, representado pela Formação Estrada dos Romeiros, composta predominantemente por metarritmitos, filitos, metassiltitos, metarenitos, além de metabásicas e metacalcários orientados segundo a direção NE-SW. O contato a noroeste encontra-se parcialmente coberto pelas rochas sedimentares da Bacia do Paraná (Godoy 1989; Godoy et al. 1992, 1994 e 1996).
O Complexo Sorocaba apresenta forma sigmoidal alongada segundo NE-SW, com exposição da ordem de $180 \mathrm{~km}^{2}$. Está cortado pelas falhas normais com direção NW-SE Doninha, ao norte, e Piragibu-Mirim, ao sul, que determinam a compartimentação em três segmentos alçados diferencialmente e com características texturais distintas. A porção oriental mede cerca de $10 \mathrm{~km}$ x $3 \mathrm{~km}$ com direção ENE-WSW paralelo à orientação da Falha de Jundiuvira; a porção central, mede cerca de $16 \mathrm{~km}$ x 4 km com direção NE-SW e a porção ocidental mede $15 \mathrm{~km}$ x 4,5 km com direção ENE-WSW.

O complexo compreende vinte tipos petrográficos, agrupados segundo características geológicas em onze fácies e/ou associações de fácies, compostas dominantemente por monzogranitos, freqüentes sienogranitos e corpos localizados de dioritos e granodioritos. As texturas mais freqüentes são as porfiríticas com presença ou não de feições rapakivi, mas termos eqüi- ineqüigranulares, aplíticos e pegmatóides também são comuns. $\mathrm{O}$ índice de coloração destes litotipos é principalmente leucocrático com variedades distintas de holo a melagranitóides. A mineralogia essencial compreende microclínio pertítico, oligoclásio e/ou andesina, quartzo e biotita, zircão, apatita, titanita, allanita, turmalina e opacos são acessórios comuns. Raras muscovita e cordierita ocorrem em fácies tardias pegmatóides com intenso processo de assimilação. A hornblenda é comum, mas, o piroxênio é raro e ocorrem nas fácies de composições dioríticas e granodiríticas (Godoy \& Figueiredo 1991 e Godoy et al. 1996).

As estruturas rúpteis são caracterizadas por zonas miloníticas e sobrepostas a elas, processos cataclásticos, restritos às 
Tabela 1 - Características petrográficas das variedades Amêndoas Sorocaba.

\begin{tabular}{|c|c|c|c|c|c|c|c|c|c|}
\hline \multirow{2}{*}{\multicolumn{4}{|c|}{$\begin{array}{l}\text { Amostra } \\
\end{array}$}} & \multicolumn{6}{|c|}{ AMÊNDOAS SOROCABA } \\
\hline & & & & ESCURO & CINZA & $B R A N C O$ & VERMELHO & ROSEO & CREME \\
\hline \multicolumn{4}{|c|}{ Microclínio } & 37 & 31 & 34 & 32 & 33 & 35 \\
\hline \multicolumn{4}{|c|}{ Plagioclásio } & 31 & 25 & 26 & 29 & 30 & 23 \\
\hline \multicolumn{4}{|c|}{ Quartzo } & 20 & 26 & 30 & 29 & 27 & 29 \\
\hline \multicolumn{4}{|c|}{ Biotita } & 20 & 15 & 8 & 7 & 8 & 8 \\
\hline \multicolumn{4}{|c|}{ Hornblenda } & $\mathrm{Tr}$ & & $\mathrm{Tr}$ & & & \\
\hline \multicolumn{4}{|c|}{ Muscovita } & & & $\operatorname{tr}$ & & & \\
\hline \multirow{6}{*}{\multicolumn{2}{|c|}{ 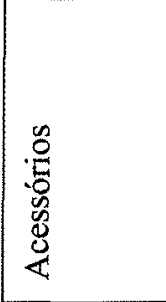 }} & & apatita & tr & & $\operatorname{tr}$ & $\operatorname{tr}$ & $\operatorname{tr}$ & $\operatorname{tr}$ \\
\hline & & & zircão & $\operatorname{tr}$ & $\operatorname{tr}$ & tr & $\operatorname{tr}$ & $\operatorname{tr}$ & tr \\
\hline & & & titanita & $\operatorname{tr}$ & $\operatorname{tr}$ & tr & $\operatorname{tr}$ & & $\operatorname{tr}$ \\
\hline & & & allanita & tr & $\operatorname{tr}$ & $\operatorname{tr}$ & $\operatorname{tr}$ & & \\
\hline & & & rutilo & $\operatorname{tr}$ & & $\operatorname{tr}$ & & & \\
\hline & & & opaco & $\operatorname{tr}$ & $\operatorname{tr}$ & $\operatorname{tr}$ & $\operatorname{tr}$ & $\operatorname{tr}$ & \\
\hline \multirow{5}{*}{\multicolumn{2}{|c|}{ 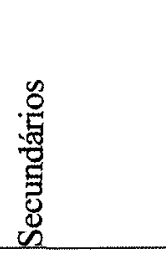 }} & & sericita & 2 & 1 & 1 & 1 & 1 & 3 \\
\hline & & & clorita & $\operatorname{tr}$ & 1 & $\operatorname{tr}$ & 1 & 1 & 1 \\
\hline & & & epidoto & & $\operatorname{tr}$ & $\operatorname{tr}$ & $\operatorname{tr}$ & $\operatorname{tr}$ & \\
\hline & & & carbonato & & & & $\operatorname{tr}$ & & \\
\hline & & & gilo-minerais & & tr & & & & \\
\hline \multicolumn{4}{|c|}{ Estrutura } & isotrópico & isotópico & isotrópico & Isotrópico & isotrópico & Isotrópico \\
\hline \multicolumn{4}{|c|}{ Textura } & porfiróide & porfiróide & porfiróide & porfiróide & porfiróide & Porfiróide \\
\hline \multicolumn{4}{|c|}{ Cor } & cinza escuro & cinza claro & cinza claro & róseo & \begin{tabular}{|l|} 
róseo \\
\end{tabular} & róseo claro \\
\hline \multicolumn{4}{|c|}{ Índice de cor } & $<20$ & 15 & 8 & 7 & 8 & 8 \\
\hline \multirow{7}{*}{ 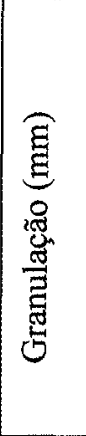 } & \multicolumn{3}{|c|}{ matriz } & média & média & $\begin{array}{l}\text { média- } \\
\text { grossa }\end{array}$ & $\begin{array}{l}\text { média- } \\
\text { grossa }\end{array}$ & média & Grossa \\
\hline & \multicolumn{3}{|c|}{ Composição } & $\mathrm{FK}$ & FK/ & FK & FK & FK & FK \\
\hline & \multicolumn{3}{|c|}{ Cor } & \begin{tabular}{|l|} 
róseo \\
\end{tabular} & branco & branco & róseo & \begin{tabular}{|l|} 
róseo \\
\end{tabular} & Róseo \\
\hline & \multirow{4}{*}{ 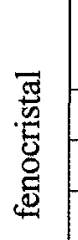 } & Forn & & \begin{tabular}{|c|}
$\begin{array}{c}\text { subeuedrais- } \\
\text { ovalados }\end{array}$ \\
\end{tabular} & \begin{tabular}{|c|} 
subeuedrais- \\
ovalados
\end{tabular} & $\begin{array}{c}\text { subeuedrais- } \\
\text { ovalados }\end{array}$ & subeuedrais & $\begin{array}{c}\text { subeuedrais- } \\
\text { ovalados }\end{array}$ & Subeuedrais \\
\hline & & Tam & nanho Máx. & $5 \mathrm{~cm}$ & $4 \mathrm{~cm}$ & $6 \mathrm{~cm}$ & $4 \mathrm{~cm}$ & $4 \mathrm{~cm}$ & $5 \mathrm{~cm}$ \\
\hline & & Tam & nanho médio & $2-3 \mathrm{~cm}$ & $3 \mathrm{~cm}$ & $2 \mathrm{~cm}$ & $2 \mathrm{~cm}$ & $1,5 \mathrm{~cm}$ & $2 \mathrm{~cm}$ \\
\hline & & Por & centagem & $<15$ & $<20$ & 25 & 30 & 25 & 35 \\
\hline \multicolumn{4}{|c|}{$\mathrm{N}^{\circ}$ de microfissuras $/ \mathrm{mm}^{2}$} & 1,7 & 1,9 & 1,3 & 1,2 & 2,0 & 0,3 \\
\hline \multirow{2}{*}{\multicolumn{3}{|c|}{$\begin{array}{c}\begin{array}{c}\text { Microfissuras } \\
(\%)\end{array} \\
\end{array}$}} & Intracristalina & 87,5 & 95,3 & 90,6 & 89,7 & 93,4 & 81,4 \\
\hline & & & Intercristalina & 12,5 & 4,7 & 9,4 & 10,3 & 6,6 & 18,6 \\
\hline \multirow{3}{*}{\multicolumn{3}{|c|}{$\begin{array}{c}\text { Contatos } \\
(\%)\end{array}$}} & $\begin{array}{l}\text { Côncavo/ } \\
\text { convexo }\end{array}$ & 56,3 & 30 & 77,3 & 78 & 88,8 & 79,5 \\
\hline & & & Reto & 31,8 & 47,7 & 20,1 & 22 & 11,2 & 20,5 \\
\hline & & & Serrilhado & 11,9 & 22,3 & 2,6 & 0 & 0 & 0 \\
\hline \multicolumn{4}{|c|}{ Alteração Mineral } & Média & Baixa & Alta & Média & Média & Baixa \\
\hline \multicolumn{4}{|c|}{ Classificação (QAP) } & monzogranito & $\begin{array}{l}\text { monzogranito } \\
\text { sienogranito }\end{array}$ & monzogranito & $\begin{array}{l}\text { monzogranito } \\
\text { sienogranito }\end{array}$ & monzogranito & Monzogranito \\
\hline
\end{tabular}

zonas de cisalhamento no contato sul/sudeste e aos falhamentos internos, sendo que estas compartimentam o complexo. A parte oriental corresponde a um bloco exposto na sua parte mais profunda e é caracterizada por maior homogeneidade de fácies, dominando os monzogranitos porfiríticos de coloração cinza, com corpos locais de granodiorito. A parte central caracteriza-se por maior número de falhas e maior diversidade de tipos litológicos, sendo que a partir do Falhamento das Doninhas, dominam granitos róseos, secundados por porfiríticos claros. Na parte sul, a partir do Falhamento de Piragibú-Mirim, dominam as fácies 
monzo-sienogranitos porfiríticos róseos.

A distribuição das fácies está representada no mapa geológico da Figura 1. São descritas seis associações de rochas com feições estéticas distintas, como as mais propícias à exploração e que serão designadas informalmente de "Amêndoa Sorocaba", nome já consagrado na literatura para um tipo de rocha ornamental deste complexo, adicionado de termos referentes a coloração dominante para estas rochas. As características petrográficas das fácies analisadas estão descritas na Tabela 1.

O tipo Amêndoa Escuro corresponde à associação mela monzogranito (F5) que são rochas isotrópicas, ineqüigranulares, porfiríticas de granulação média, escura, com índices de cor entre $10 \%$ e $20 \%$, com a presença de feldspato róseo com dimensões de até $5 \mathrm{~cm}$ e de plagioclásio com até $1 \mathrm{~cm}$. Observa-se distribuição bimodal da granulação, com valores médios de $4 \mathrm{~cm}$ e uma outra, em torno de $2 \mathrm{~cm}$ exibindo localmente texturas rapakivi. A matriz de granulação média e escura é preferencialmente quartzo-diorítica a granodiorítica, apresentando variações modais em função da porcentagem dos fenocristais (Figura 2 A).

O tipo Amêndoa Cinza corresponde à associação monzosienogranito cinza (F2), é identificado por variedades leucocrática, isotrópicas, ineqüigranulares, porfiríticas, compostas por fenocristais de feldspato potássico cinza com dimensões de 1 $\mathrm{cm}$ a $4 \mathrm{~cm}$ e plagioclásios branco de dimensões entre $0,5 \mathrm{~cm}$ a $1 \mathrm{~cm}$, imersos em matriz de granulação média de composição quartzo-feldspática com biotita. Ocorre distribuição bimodal dos feldspatos potássicos, havendo uma população com dimensão média de $3 \mathrm{~cm}$ e outra de $1 \mathrm{~cm}$ (Figura 2B).

O tipo Amêndoa Branco corresponde à associação de monzogranito cinza claro (F3) que consiste de rochas de coloração cinza claro, leucocráticas, ineqüigranulares, porfiríticas, ricas em fenocristais de feldspato potássico, com dimensões ao redor de $2 \mathrm{~cm}$, esporadicamente até $6 \mathrm{~cm}$, plagioclásio com até $1 \mathrm{~cm}$ e porcentagem de biotita inferior a $8 \%$ (Figura 2C).

O tipo Amêndoa Vermelho ou "Amêndoa Sorocaba" denominação já consagrada na literatura corresponde à associação monzo-sienogranito róseo (F7), constituída por rochas isotrópicas, ineqüigranulares, porfiríticas de matriz média a grossa e composição quartzo-feldspática com biotita, em que se destacam megacristais de feldspato potássico róseo (com ou sem textura rapakivi) e plagioclásio branco. São dominantemente monzogranitos a localmente sienogranitos, com termos diferenciados em função da porcentagem média das biotitas, do tamanho e da variação da porcentagem dos megacristais de até $30 \%$ (Figura 2D).

O tipo Amêndoa Róseo corresponde à associação monzogranito rósea $(\mathrm{F} 8)$ representada por rochas leucocráticas, isotrópicas, ineqüigranulares e porfiríticas. São compostas por fenocristais róseos de feldspato potássico de até $4 \mathrm{~cm}$, localmente com textura rapakivi e plagioclásio branco com até $1 \mathrm{~cm}$, numa matriz de granulação média rica em quartzo e feldspatos, além de biotita (Figura 2E).

O tipo Amêndoa Creme corresponde a uma das fácies monzograníticas identificada na associação dos monzogranitos róseos (F8) com expressão mais restrita. É constituída por rochas leucocráticas, maculadas, isotrópicas, ineqüigranulares, porfiríticas, com predomínio de quase $50 \%$ da rocha em fenocristais de feldspato potássico. Corresponde a uma variação textural, distinguida em função da granulação da matriz, porcentagem de biotita, tamanho médio dos fenocristais de feldspato potássico e de sua coloração, rósea mais clara ou, às vezes, esverdeada devido à epidotização do plagioclásio (Figura 2F).

ASPECTOS GEOQUÍMICOS As análises geoquímicas das variedades foram realizadas no Laboratório de Geoquímica do DPM/IGCE/UNESP e serão discutidas quanto ao padrão de distribuição dos elementos maiores com vista à caracterização dos litotipos correlacionados à distribuição mineralógica nas rochas. $\mathrm{Na}$ Tabela 2 apresenta-se as análises geoquímicas dos elementos maiores das fácies estudadas, possibilitando a visualização do intervalo de variação dos elementos maiores para cada fácies.

Os valores de $\mathrm{SiO}_{2}$ das fácies analisadas variam entre 68 e $72 \%$. Os valores de $\mathrm{TiO}_{2}$ são variáveis nas fácies analisadas, apresentando-se mais elevados devido às quantidades maiores de minerais acessórios, como titanita e rutilo, podendo, portanto, refletir em processo de alteração e conseqüentemente manchar de amarelo a avermelho, pontualmente as placas.

Os teores de $\mathrm{Al}_{2} \mathrm{O}_{3}$ também apresentam diferenças entre as diversas variedades, mostrando valores mais elevados para as rochas mais ricas em biotita. Estes altos valores de alumínio e, conseqüentemente, de biotita se refletem na menor resistência mecânica e na alterabilidade dos tipos estudados, especialmente se submetidos a substâncias com $\mathrm{pH}$ muito ácido ou muito básico.

$\mathrm{O} \mathrm{Fe} \mathrm{O}_{3}$ está diretamente correlacionado à presença de minerais máficos (biotita e/ou hornblenda) e à presença dos minerais opacos (magnetita e ilmenita). Rochas com maiores teores de $\mathrm{Fe}$, especialmente opacos, propiciam a geração de hidróxidos de Fe, quando em ambientes úmidos, podendo ocorrer o aparecimento de manchas avermelhadas ou amareladas, fenômeno acompanhado de expansão volumétrica. Os valores de $\mathrm{CaO}$ e $\mathrm{MgO}$ são reffexos diretos da mineralogia, em razão de quantidades mais elevadas de hornblenda.

Os valores de $\mathrm{K}_{2} \mathrm{O}$ e $\mathrm{Na}_{2} \mathrm{O}$ são altos, característico das rochas ácidas, mas com pequenas diferenças entre os litotipos.

CARACTERIZAÇÃO TECNOLÓGICA Esta etapa contemplou a realização dos principais ensaios para a determinação das propriedades físicas e mecânicas, obedecendo aos procedimentos normativos apresentados pela ABNT (Associação Brasileira de Normas Técnicas) e ASTM (American Society for Testing and Materials). As análises foram realizadas no Laboratório de Rochas Ornamentais do DPM/ICGE/UNESP e como referência para comparação dos dados obtidos foram utilizados os valores referenciais para rochas graníticas sugeridos pela norma C-615 da ASTM (1999), por Frazão e Farjallat (1995) e os dados apresentados para o Amêndoa Sorocaba nos trabalhos de IPT (2000 e 2004), conforme apresentado na Tabela 3.

Os parâmetros massa especifica aparente, porosidade aparente e absorção d'água (Tabela 3) foram analisados segundo a norma NBR 12766 (ABNT 1992a). A porosidade aparente e a absorção d'água apresentam valores típicos para rochas graníticas e pouco variáveis entre si, refletindo a forma, contatos minerais e granulação semelhantes das amostras. Valores ligeiramente mais altos de porosidade aparente e de absorção d'água para o tipo Cinza podem ocorrer eventualmente, em virtude de pontos dispersos em que a alteração de minerais máficos e, mais raramente, dos feldspatos está mais desenvolvida, chegando a formar cavidades de até $3,0 \mathrm{~mm}$. Valores menores de porosidade aparente e de absorção d'água para o tipo Escuro são vinculados à granulação mais fina da matriz. Os valores obtidos para esses materiais não restringem a aplicação em ambientes úmidos de interiores e exteriores, mas ressalta-se que a presença de raras cavidades provenientes de alterações minerais naturais nesses tipos, deve ser monitorada durante o processo produtivo. Essas 

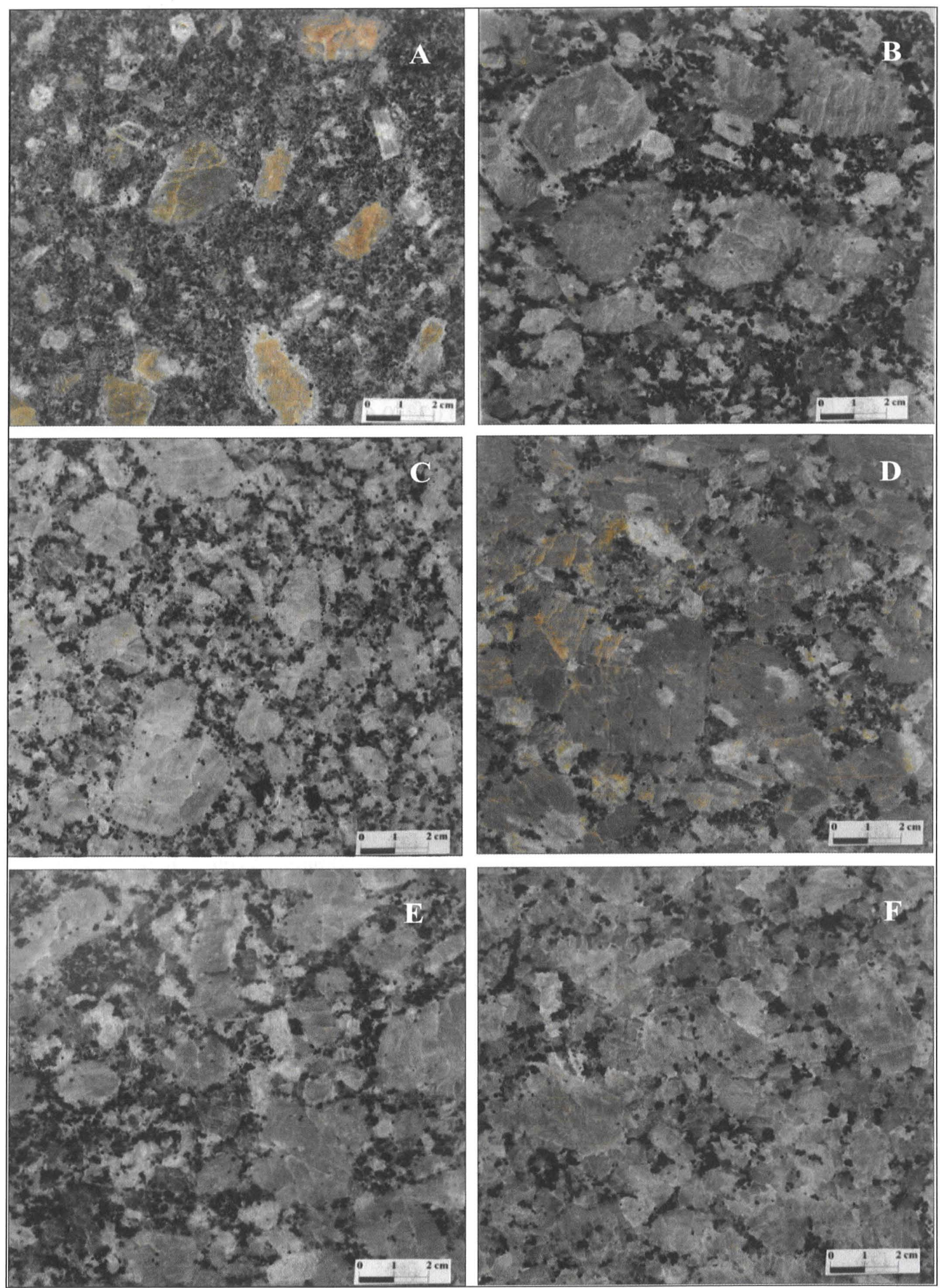

Figura 2: Aspecto macroscópico de amostras polidas de rochas do Complexo Sorocaba. 
Tabela 2 - Análises geoquímicas de elementos maiores das rochas do Complexo Sorocaba.

\begin{tabular}{|c|c|c|c|c|c|c|c|c|c|c|c|}
\hline & Amostra & $\mathrm{SiO}_{2}$ & $\mathrm{TiO}_{2}$ & $\mathrm{Al}_{2} \mathrm{O}_{3}$ & $\mathrm{Fe}_{2} \mathrm{O}$ & MnO & MgO & $\mathrm{CaO}$ & $\mathrm{Na}_{2} \mathrm{O}$ & $\mathbf{K}_{2} \mathbf{O}$ & $\mathbf{P}_{2} \mathbf{O}_{5}$ \\
\hline \multirow{3}{*}{ 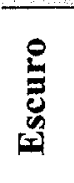 } & SO-1 & 65,00 & 1,03 & 15,69 & 4,59 & 0,08 & 1,10 & 3,36 & 3,19 & 4,73 & 0,44 \\
\hline & $\mathrm{SO}-1$ & 65,10 & 1,07 & 15,87 & 5,02 & 0,09 & 1,11 & 3,06 & 3,01 & 5,28 & 0,36 \\
\hline & SO-1 & 66,60 & 1,42 & 13,87 & 5,10 & 0,06 & 1,71 & 1,62 & 3,22 & 4,97 & 0,25 \\
\hline \multirow{3}{*}{ జ్ } & $\mathrm{SO}-2$ & 68,10 & 0,62 & 14,90 & 5,16 & 0,09 & 0,75 & 1,61 & 2,83 & 5,47 & 0,25 \\
\hline & $\mathrm{SO}-2$ & 70,70 & 0,58 & 14,11 & 4,51 & 0,06 & 0,22 & 1,51 & 3,00 & 3,97 & 0,30 \\
\hline & $\mathrm{SO}-2$ & 71,61 & 0,13 & 13,06 & 4,20 & 0,03 & 0,08 & 0,40 & 2,66 & 6,63 & 0,05 \\
\hline \multirow{3}{*}{ 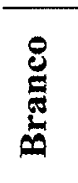 } & $\mathrm{SO}-3$ & 70,72 & 0,56 & 14,30 & 3,96 & 0,08 & 0,53 & 1,44 & 2,74 & 5,13 & 0,15 \\
\hline & $\mathrm{SO}-3$ & 71,52 & 0,35 & 15,04 & 2,68 & 0,06 & 0,42 & 1,19 & 2,76 & 5,81 & 0,13 \\
\hline & $\mathrm{SO}-3$ & 73,50 & 0,71 & 12,39 & 2,53 & 0,04 & 0,76 & 0,91 & 3,01 & 4,92 & 0,08 \\
\hline \multirow{3}{*}{ 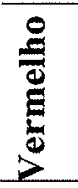 } & $\mathrm{SO}-4$ & 70,27 & 0,38 & 13,86 & 2,76 & 0,04 & 0,34 & 1,52 & 3,66 & 6,11 & 0,14 \\
\hline & $\mathrm{SO}-4$ & 70,45 & 0,59 & 13,78 & 4,10 & 0,07 & 0,68 & 1,74 & 2,77 & 5,19 & 0,19 \\
\hline & $\mathrm{SO}-4$ & 71,92 & 0,43 & 13,71 & 2,92 & 0,05 & 0,48 & 1,43 & 2,87 & 6,04 & 0,13 \\
\hline \multirow{3}{*}{ 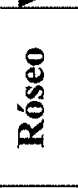 } & $\mathrm{SO}-5$ & 69,90 & 0,54 & 14,06 & 4,36 & 0,08 & 0,55 & 1,71 & 3,05 & 5,21 & 0,18 \\
\hline & $\mathrm{SO}-5$ & 70,73 & 0,57 & 15,35 & 5,41 & 0,10 & 0,91 & 1,69 & 2,25 & 2,29 & 0,06 \\
\hline & SO-5 & 70,55 & 0,50 & 14,02 & 4,02 & 0,07 & 0,54 & 1,63 & 2,76 & 5,28 & 0,17 \\
\hline \multirow{3}{*}{$\begin{array}{l}\text { Uू } \\
\text { Uू }\end{array}$} & SO-6 & 70,30 & 0,80 & 13,85 & 2,18 & 0,04 & 0,92 & 1,10 & 3,36 & 5,62 & 0,11 \\
\hline & $\mathrm{SO}-6$ & 71,34 & 0,57 & 13,37 & 4,40 & 0,08 & 0,72 & 1,64 & 2,61 & 5,06 & 0,19 \\
\hline & SO-6 & 71,64 & 0,61 & 12,94 & 4,08 & 0,07 & 0,66 & 1,73 & 2,68 & 4,92 & 0,20 \\
\hline
\end{tabular}

Tabela 3 - Resultados dos ensaios tecnológicos para as amostras do Complexo Sorocaba, obtidos neste trabalho, publicados por IPT (2000) e valores limitrofes sugeridos pela norma C 615 (ASTM 1999) e por Frazão \& Farjallat (1995)

\begin{tabular}{|c|c|c|c|c|c|c|c|c|c|}
\hline \multirow[b]{2}{*}{ Grupo A } & \multirow{2}{*}{$\begin{array}{c}615 \\
(\mathrm{ASTH} \\
(1999)\end{array}$} & \multirow{2}{*}{$\begin{array}{l}\text { Frazâo \& } \\
\text { Farjallat } \\
(\mathbf{1 9 9 5})\end{array}$} & \multicolumn{7}{|c|}{ Amêndoas Sorocaba } \\
\hline & & & $\begin{array}{l}\text { IPT } \\
(\mathbf{2 0 0 0})\end{array}$ & Escuro & Cinza & Branco & Verm. & Rosa & Creme \\
\hline $\begin{array}{c}\text { Porosidade } \\
\text { aparente }(\%)\end{array}$ & n.e. & $\leq 1,0$ & 0,59 & 0,42 & 0,90 & 0,69 & 0,69 & 0,60 & 0,69 \\
\hline $\begin{array}{c}\text { Absorção } \\
\text { d'água (\%) } \\
\end{array}$ & $\leq 0,4$ & $\leq 0,4$ & 0,22 & 0,16 & 0,34 & 0,26 & 0,26 & 0,22 & 0,26 \\
\hline $\begin{array}{l}\text { Massa específica } \\
\text { seca }\left(\mathrm{kg} / \mathrm{m}^{3}\right)\end{array}$ & $\geq 2560$ & $\geq 2550$ & 2720 & 2700 & 2670 & 2700 & 2660 & 2670 & 2660 \\
\hline $\begin{array}{l}\text { Desgaste } \text { Amsler } \\
\text { (mm) }\end{array}$ & n.e. & $\leq 1,0$ & 0,86 & 0,58 & 0,51 & 0,73 & 0,74 & 0,60 & 0,74 \\
\hline $\begin{array}{c}\text { Modulo de } \\
\text { Ruptura (MPa) }\end{array}$ & $\geq 10,34$ & $\geq 10,0$ & 11,3 & 14,82 & 12,68 & 10,85 & 10,40 & 11,06 & 10,60 \\
\hline $\begin{array}{c}\text { Compressão } \\
\text { uniaxial (MPa) }\end{array}$ & $\geq 131$ & $\geq 100$ & 164,5 & 154 & 151 & 119 & 175 & 121 & 124 \\
\hline $\begin{array}{c}\text { Vp (compressão } \\
\text { uniaxial) }(\mathrm{m} / \mathrm{s})\end{array}$ & n.e. & $\geq 4000$ & n.e & 5181 & 4427 & 4292 & 4632 & 4949 & 4129 \\
\hline $\begin{array}{l}\text { Vp (módulo de } \\
\text { ruptura) }(\mathrm{m} / \mathrm{s})\end{array}$ & n.e & $\geq 4000$ & n.e & 5040 & 4430 & 4602 & 4761 & 4816 & 4554 \\
\hline $\begin{array}{c}\text { Coeficiente de } \\
\text { Dilatação } \\
\left(10^{-3} \mathrm{~mm} / \mathrm{m}^{\circ} \mathrm{C}\right)\end{array}$ & n.e & $<12$ & n.e & 5,54 & 6,15 & 8,05 & 7,85 & 9,55 & 7,25 \\
\hline
\end{tabular}




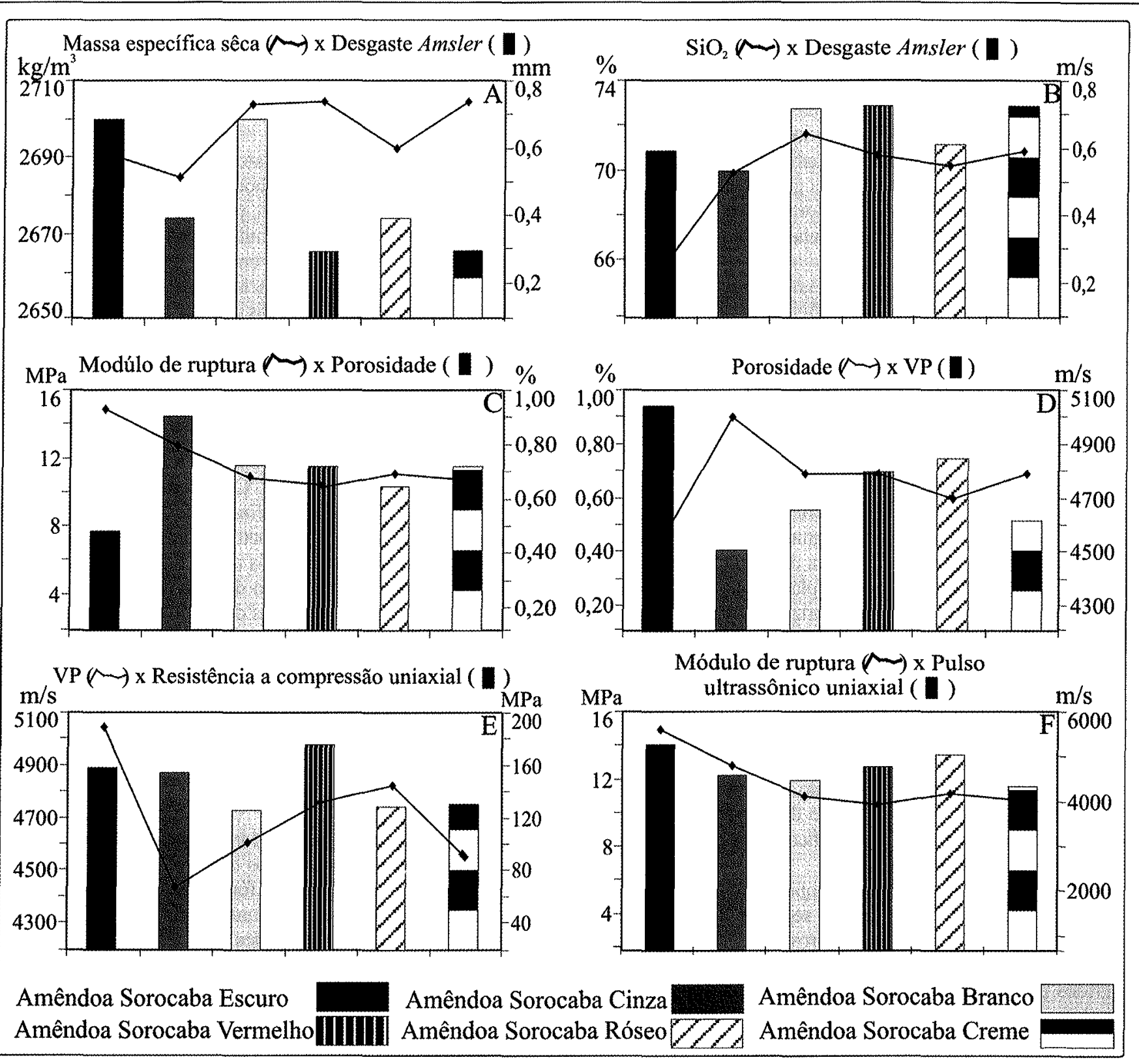

Figura 3: Correlação entre algumas das propriedades tecnológicas avaliadas para as rochas do Complexo Sorocaba.

feições e o possível efeito deletério que possam causar à rocha dependendo de sua utilização final podem ser mitigados, ainda na fase de beneficiamento, pela aplicação de resinas, tecnologia atualmente bastante difundida no mercado. A utilização desse recurso e a verificação de sua eficácia devem ser avaliadas com métodos laboratoriais específicos.

Os valores de massa específica aparente seca encontram-se acima dos valores de referência adotados, sendo muito próximos e refletindo a similaridade composicional entre as amostras. Valores mais elevados estão diretamente relacionados à presença na matriz de quantidades mais elevadas de hornblenda e/ou biotita.

O ensaio para determinação do desgaste abrasivo Amsler, seguiu-se à norma NBR 12042 (ABNT 1992b) e todos os valores obtidos mostram-se inferiores ao valor proposto por Frazão \& Farjallat (1995). Os valores baixos são reflexos da granulação da matriz, do tamanho dos fenocristais e das microgranulações do quartzo presente. Dessa forma os valores de desgaste não são proibitivos para a aplicação dessas rochas como revestimentos de pisos, cabendo, entretanto, bastante cuidado para a aplicação em pisos de alto tráfego, especialmente em exteriores, pois sob determinadas condições de trânsito, podem apresentar erosão diferencial devido a diferença de dureza média dos minerais da matriz e dos fenocristais. Ressalta-se ainda que os tipos mais escuros tendem a apresentar uma perda de brilho mais acentuada que as demais variedades. Para as rochas analisadas observou-se que o desgaste Amsler apresenta baixa correlação com a massa específica (Figura 3A) e relação inversamente proporcional com os teores de $\mathrm{SiO}_{2}$ (Figura 3B).

Os valores de módulo de ruptura foram obtidos segundo a norma NBR 12763 (ABNT 1992c). Os resultados foram muito próximos aos limites dos valores de referência adotados, sendo que os tipos Escuro e Cinza apresentaram o melhor desempenho, provavelmente devido à porcentagem e tamanho de minerais micáceos da matriz. Os baixos valores de módulo de ruptura, comuns em rochas porfiríticas, são devidos principalmente ao caráter grosso e ineqüigranular dessas rochas, havendo influência significativa do microfissuramento e planos de clivagem dos fenocristais de feldspato, feições de descontinuidades que 
aliviam as tensões, como sugere a correlação com porosidade aparente (Figura 3C). Uma solução tecnológica simples é o aumento da espessura das placas, o que dependendo do tipo de aplicação, garante a resistência mecânica sem exigir grandes alterações de projeto para o suporte da placa, visto a massa específica das rochas analisadas. Outra solução simples e adotada com freqüência cada vez maior na atualidade é a fixação de telas com resinas no tardoz das placas para garantir maior resistência mecânica. Em virtude dos baixos valores desse parâmetro recomenda-se a realização de estudos detalhados para a aplicação em fachadas.

Os valores de resistência à compressão uniaxial simples, obtidos segundo a norma NBR 12767 (ABNT 1992d), são superiores a $100 \mathrm{MPa}$, limite proposto por Frazão \& Farjallat (1995), sendo que os tipos Amêndoa Branco, Amêndoa Rosa e Amêndoa Creme apresentam tensões abaixo de $131 \mathrm{MPa}$, conforme proposto pela norma C 615 (ASTM 1999). Os tipos de contato entre minerais, textura heterogênea, grossa e ineqüigranular e o microfissuramento e planos de clivagem dos fenocristais de feldspato relativamente alto, são os responsáveis pelo desempenho mecânico de alguns destes materiais. $O$ tipo Vermelho apresenta maior resistência à compressão, embora seja a rocha de granulação mais grossa. Sua resistência é devida, provavelmente, a uma combinação de contatos côncavo-convexo, lobulados e planos que freqüentemente ocorre nos cristais de quartzo da matriz e resultam em um bom entrelaçamento mineral não observado nas demais variedades. Os tipos Amêndoa Escuro e Amêndoa Cinza apresentam resistência intermediária, devido à matriz fina e média respectivamente. Os demais tipos apresentam menor tensão de ruptura, em função da granulação média a grossa, microfissuramento e planos de clivagem nos fenocristais de feldspato potássico.

Normalmente os valores de módulo de ruptura de rochas correspondem a $10 \%$ do valor de tensão da resistência a compressão, sendo comum para rochas porfiríticas valores entre $6 \%$ e $8 \%$, como ocorre com o tipo Vermelho.

Os valores de velocidade de propagação de ondas ultrasônicas longitudinais ( $V p$ ), obtidos segundo a norma D 2845 (ASTM 1990) para os corpos-de-prova dos ensaios de compressão e módulo de ruptura (Tabela 3), estão acima dos limites sugeridos por Frazão \& Farjallat (1995) e são devidos, sobretudo, à granulação heterogênea e grossa que apresentam as variedades analisadas. Os valores de Vp são um indicativo das descontinuidades das rochas e são inversamente proporcionais à porosidade (Figura $3 \mathrm{D}$ ). Relacionam-se também com a resistência à compressão uniaxial (Figura 3E), ambos com decréscimo à medida que a granulação aumenta (da mais fina para a grossa). Observa-se o mesmo comportamento para os dados de módulo de ruptura e $\mathrm{Vp}$ (Figura $3 \mathrm{~F}$ ).

Os ensaios para determinação do coeficiente de dilatação térmica linear, seguiu a preconização da norma NBR 12765 (ABNT 1992), forneceram valores variáveis típicos para rochas graníticas (Tabela 3) conforme Rzhevsky \& Novik (1971) e concordantes com os sugerido por Frazão \& Farjallat (1995). Embora as rochas estudadas não mostrem amplas variações mineralógicas os coeficientes obtidos variaram no intervalo relativamente amplo, entre $5,54 \times 10^{-3} \mathrm{~mm} / \mathrm{m}^{\circ} \mathrm{C}$ e $9,55 \times 10^{-3} \mathrm{~mm} / \mathrm{m}^{\circ} \mathrm{C}$, provavelmente devido as variações texturais e ao microfissuramento que apresentam. Esses dados devem ser aplicados em projetos de fachadas e situações em que a rocha esteja sujeita à variações amplas de temperatura.

Os resultados obtidos nos ensaios tecnológicos das variedades consideradas apontam para um bom desempenho dessas rochas como material para revestimento, pois em sua maioria os dados obtidos situam-se dentro dos limites freqüentemente utilizados como referência. Para os casos em que os valores obtidos são pouco mais baixos que as referências adotadas, não implica dizer que sua aplicação está vetada, mas sim que a fase de projeto deve ter atenção especial para as situações em que essas propriedades sejam requeridas, objetivando o correto dimensionamento.

Como recomendações, destaca-se que em ambientes de alto tráfego ou sujeitos a ventos fortes e emissão de poeira, os tipos mais escuros devem ser evitados pela tendência que apresentam em realçar a perda de brilho sob condições de abrasão, comparativamente aos tipos mais claros. Considerando-se fachadas, salienta-se a importância para a realização de estudos adequados visando o dimensionamento (geometria e dimensões especialmente a espessura) das placas destinadas a essa finalidade, posto que as rochas ora analisadas, em função da textura porfirítica e heterogênea, apresentam baixos valores de módulo de ruptura. As porções com cavidades originadas por alteração mineral, requerem a pesquisa e adoção de medidas mitigadoras, como a impregnação com resinas já comentada anteriormente. A boa utilização e valorização desses materiais como elemento de revestimento pode ser assegurada pela desses cuidados e recomendações relativamente simples e difundidas.

CONSIDERAÇÕES FINAIS O Complexo Sorocaba apresenta ampla variedade de rochas com textura porfirítica, representando diferentes padrões estéticos com volume suficiente para a extração de blocos. Inicialmente foram definidas seis fácies mais favoráveis, mas sendo possível numa nova reavaliação, a ampliação dos estudos para outras fácies que nesta primeira fase não foram selecionadas.

Do ponto de vista tecnológico, os materiais analisados apresentam resultados que sugerem sua aplicação como elemento de revestimento de ambientes interiores e exteriores, em pisos, paredes e fachadas, desde que observados alguns quesitos importantes como a intensidade do tráfego, quando aplicado em pisos, e a espessura e dimensão das placas, quando aplicado em fachadas.

Como trabalhos futuros recomendam-se estudos de cubagem e viabilidade econômica dos depósitos desses complexos e a realização de estudos de alterabilidade e ensaios de resistência ao manchamento e ataque químico para complementação dos dados aqui apresentados.

Agradecimentos AFAPESP pelo apoio financeiro recebido (proc. $\mathrm{n}^{\mathrm{o}}$ : 00/00762-8 e 03/02860-5).

\section{Referências}

ABNT- Associação Brasileira de Normas Técnicas. 1992a. Rochas para Revestimento. Determinação da massa especifica aparente, porosidade aparente e absorção d'água aparente. 2p. (norma NBR 12766).

ABNT- Associação Brasileira de Normas Técnicas. 1992b. Materiais inorgânicos, Determinação do desgaste por abrasão. 3p. (norma NBR 12042).
ABNT- Associação Brasileira de Normas Técnicas. 1992c. Rochas para Revestimento. Determinação da resistência à flexão. 3p. (norma NBR 12763)

ABNT-Associação Brasileira de Normas Técnicas. 1992d. Rochas para revestimento. Determinaçâo da resistência à compressão uniaxial. 2p. (norma NBR 12767).

ABNT- Associação Brasileira de Normas Técnicas. 1992e. Rochas para 
Revestimento. Determinação do coeficiente de dilatação térmica. 3p. (norma NBR 12765).

ASTM-American Society For Testing And Materials. 1990. Standard test method for laboratory determination of pulse velocities and ultrasonic elastic constants of rock. (Standard ASTM D 2845). Philadelphia, USA.

ASTM- American Society For Testing And Materials. 1999. Standard specification for granite dimension stone. (Standard ASTM C 615). $2 p$. Philadelphia, USA.

Frazão E.B. \& Farjallat J.E.S. 1995. Características tecnológicas das principais rochas silicáticas brasileiras usadas como pedras de revestimento. In: Congr. Intern. da Pedra Natural, 1, Lisboa, Portugal, Atas, p. 47-58.

Godoy A.M. 1989. Caracterização faciológica, petrográfica e geoquímica dos Maciços Sorocaba e São Francisco, SP. Tese Doutoramento, Instituto de Geociências - Universidade de São Paulo, S. Paulo, $221 \mathrm{p}$

Godoy A.M. \& Figueiredo M.C.H. 1991. Caracterização faciológico e petrográfico do Maciço Granitóide Sorocaba (SP). In: SBG, Simp. Geol. Sudeste, 2, Atas, p.131-138.

Godoy A.M. \& Hackspacher P.C., Oliveira M.A.F. 1996. Geologia da
Região de Sorocaba- SP. Geociências, nº Especial, 15:89-110.

Godoy A.M., Wernick E., Dienfenbach K.W. 1992. Arquitetura e Ciclos Magmáticos do Complexo Rapakivi Sorocaba, SP. In: SBG, Congr. Brás: Geol., 37, Boletim 1, p. 329-330.

Godoy A.M., Hackspacher P.C., Oliveira M.A.F., Castro J. 1994. Geologia das Folhas Sorocaba, Brigadeiro Tobias e Sananduva, SP, em 1:25.000. In: SBG: Congr. Brás. Geol., 38, Atas, vol. 3, p. 97-8.

IPT Instituto de Pesquisas Tecnológicas do Estado de São Paulo. 2000. Rochas ornamentais e de revestimento do Estado de São Paulo. Coordenado por M.H.B. de O. Frascá.: SCTDE, São Paulo, CDROOM. (Publicação IPT 2651), v. 5, p. 2193-2204.

IPT Instituto de Pesquisas Tecnológicas do Estado de São Paulo. 2004. A cadeia produtiva de Rochas Ornamentais e para revestimento no Estado de São Paulo. Coord. Ivan S. de C. Mello. SCTDE, São Paulo, CDD-624.1832098161, p. 191.

Rzhevsky V. \& Novik G. 1971. The Physics of Rocks. MIR Publishers, Moscow, 320p. 